\title{
A DYNAMIC APPROACH TO THE EVALUATION OF OESTROGENIC EFFECTS ON THE VAGINAL EPITHELIUM IN WOMEN
}

\author{
R. STUPNIGKI AND J. TETER \\ Polish Academy of Sciences, Institute of Animal Physiology and Nutrition, \\ Department of Endocrinology, Jablonna near Warsaw, Poland, and Department of \\ Clinical Endocrinology, Medical Academy in Warsaw, Poland
}

(Received 2nd January 1970)

Several methods of estimating the oestrogenic effects (oestrogenicity) of synthetic sex-steroid compounds are currently in use. Those that are based on cytological criteria mostly utilize the so-called Maturation Index (MI) which gives percentage values for the three types of vaginal cells: parabasal $(\mathbf{P})$, intermediate (I), and superficial (S). The MI is usually expressed in the sequence, P - I - S. It is a morphological index, includes all classes of cells and can be easily reduced to numerical evaluation. The criteria accepted by the International Academy of Cytology are usually applied in the identification of such cells (Frost, 1961; Meisels, 1967, 1968; Haskins, Moszkowski \& Whitelock, 1968; Pundel, 1968; Teter, 1968).

Three other indices for the measurement of oestrogenic effects on the maturation of vaginal cells are in common use:

1. The Karyopycnotic Index (KPI). This represents the ratio of the number of mature squamous cells, regardless of their cytoplasmic staining reaction, which contain a pycnotic nucleus to the number of mature squamous cells containing a vesicular nucleus.

2. The Superficial Cell Index (SCI). This represents the ratio of the number of superficial cells, i.e. mature cells with pycnotic nuclei, to all squamous cells (Wied, 1968).

3. The Maturation Value (MV). This assigns certain values to each cell type (superficial cells, 1.0; intermediate cells, 0.5 ; parabasal cells 0.0 ). Thus, a specimen consisting only of parabasal cells would have an MV of zero (Meisels, 1967, 1968).

When considering a form of oestrogen replacement therapy, two MI patterns are to be taken into account: the initial pattern, before starting the treatment, and the terminal pattern, after ending the treatment. These may be written as:

$$
\begin{aligned}
& P_{o}-I_{o}-S_{o} \text { (initial), and } \\
& P_{t}-I_{t}-S_{t} \text { (terminal) }
\end{aligned}
$$

If all types of cells are present in the initial state and the vaginal epithelium responds to the treatment, then two shifts due to maturation may take place: 
$\mathrm{P} \rightarrow \mathrm{I}$, and $\mathrm{I} \rightarrow \mathrm{S}$. A change in the $\mathrm{MI}$ of a patient, due to oestrogen treatment, may be represented by the difference $(\Delta)$ between the terminal and initial values of either of the oestrogenicity indices previously mentioned.

It is evident, however, that neither $\Delta \mathrm{SCI}$ nor $\Delta \mathrm{MV}$ can provide the required information, since SGI represents only the second maturation shift $(\mathrm{I} \rightarrow \mathrm{S})$, while the MV contains a component, $0.5 \mathrm{I}$, which does not necessarily reflect maturation changes. Its use in studying the dynamics of oestrogen effects is, therefore, questionable.

In order to overcome these inconveniences, the concept was formulated of an overall change in the two MI patterns. When, for instance, the MIs before and after treatment are 20-75-5, and $0-75-25$, respectively, two shifts are plainly visible, $P_{0} \rightarrow P_{t}$, or the number of parabasal cells which became intermediate, and $S_{1} \rightarrow S_{0}$, or the number of newly matured superficial cells. The overall change is, therefore, $20-0+25-5=40$.

The two shifts may not be equivalent to each other, i.e. one of the shifts may be more sensitive to the oestrogenic stimulus than the other. Thus, in order to balance the overall change, the value of one of the shifts should be multiplied by a correction factor, in this case the so-called relative discrimination coefficient (Fisher, 1948). In the present study, this was calculated from data recorded for forty women receiving 0.02 or $0.05 \mathrm{mg}$ of ethinyl-oestradiol daily for a period of 10 days; it amounted to 0.07 for the first shift. In order to facilitate routine calculations, it was rounded up to $0 \cdot 1$. The balanced overall change (BOG) is calculated as follows:

$$
\mathrm{BOC}=0 \cdot 1\left(\mathrm{P}_{\mathrm{o}}-\mathrm{P}_{\mathrm{t}}\right)+\left(\mathrm{S}_{\mathrm{t}}-\mathrm{S}_{\mathrm{o}}\right)
$$

Three examples are taken from Table 1 as an illustration:

\begin{tabular}{lcrcc}
\cline { 2 - 5 } A Initial (o) & MI & SCI & MV & BOC \\
\cline { 2 - 5 } Terminal (t) & $80-15-5$ & 5 & 12 & - \\
& $10-85-5$ & 5 & 47 & $\overline{7}$ \\
B & $\Delta$ & 0 & 35 & 7 \\
\cline { 2 - 5 } & $90-10-0$ & 0 & 5 & - \\
& $0-80-20$ & 20 & 60 & $\overline{-}$ \\
C & $\Delta$ & 20 & 55 & 29 \\
\hline & $10-90-0$ & 0 & 45 & - \\
& $0-60-40$ & 40 & 70 & - \\
& $\Delta$ & 40 & 25 & 41 \\
\hline
\end{tabular}

In $\mathrm{A}$ and $\mathrm{B}$, both $\triangle \mathrm{SGI}$ and $\triangle \mathrm{MV}$ evidently give wrong answers: the former is an underestimate, the latter seems to be an overestimate. In $\mathrm{C}$, the situation is reversed, and the $\Delta \mathrm{MV}$ is distinctly underestimated. Thus, it seems that the proposed concept of balanced overall change is a better representation of the vaginal epithelial response to oestrogen treatment than either of the other two indices.

When group comparisons are to be made, however, it should be remembered that with increasing mean effects, the variability of individual results also increase. Since this variability is proportional to the square root of the mean, 
which is a general property of most enumeration (discrete) characteristics (cf. Snedecor, 1956), in order to make such variations approximately constant and independent from the means, the square roots of the BOG values ought to be calculated. These values were called the Dynamic Oestrogenicity Index (DEI).

$$
\mathrm{DEI}=\sqrt{\mathrm{BOC}}=\sqrt{0 \cdot 1\left(\mathrm{P}_{\mathrm{o}}-\mathrm{P}_{\mathrm{t}}\right)+\left(\mathrm{S}_{\mathrm{t}}-\mathrm{S}_{\mathrm{o}}\right)}
$$

A comparison was made of the DEI with the KI and the MV index.

TABLE 1

COMPARISON OF EFFECTS OF OESTROGEN TREATMENT ON THE VAGINAL EPITHELIUM IN AMENORRHOEIC WOMEN AS MEASURED BY THREE DIFFERENT OESTROGENICITY INDICES*

\begin{tabular}{|c|c|c|c|c|c|c|}
\hline $\begin{array}{l}\text { Daily oestrogen } \\
\text { dose }(\mathrm{mg})\end{array}$ & $\log d o s e$ & Initial & Terminal & $M V$ & $S C I$ & $D E I$ \\
\hline \multirow[t]{2}{*}{0.02} & \multirow[t]{2}{*}{$0 \cdot 3$} & \multirow[t]{2}{*}{$\begin{array}{c}20-80-0 \\
100-0-0 \\
0-98-2 \\
0-90-10 \\
80-15-5 \\
0-100-0 \\
40-60-0 \\
0-100-0 \\
0-100-0 \\
5-95-0\end{array}$} & $\begin{array}{c}0-95-5 \\
0-90-10 \\
0-70-30 \\
0-75-25 \\
10-85-5 \\
0-95-5 \\
0-80-20 \\
0-95-5 \\
0-98-2 \\
0-88-12\end{array}$ & $\begin{array}{r}12 \\
55 \\
14 \\
7 \\
35 \\
2 \\
30 \\
2 \\
1 \\
9\end{array}$ & $\begin{array}{r}5 \\
10 \\
28 \\
15 \\
0 \\
5 \\
20 \\
5 \\
2 \\
12\end{array}$ & $\begin{array}{l}2 \cdot 6 \\
4 \cdot 5 \\
5 \cdot 3 \\
3 \cdot 9 \\
2 \cdot 6 \\
2 \cdot 2 \\
4 \cdot 9 \\
2 \cdot 2 \\
1 \cdot 4 \\
3 \cdot 5\end{array}$ \\
\hline & & & $\begin{array}{l}\text { Mean } \\
\text { S.D. }\end{array}$ & $\begin{array}{l}16 \cdot 7 \\
17 \cdot 7\end{array}$ & $\begin{array}{r}10 \cdot 2 \\
8 \cdot 8\end{array}$ & $\begin{array}{l}3 \cdot 31 \\
1 \cdot 31\end{array}$ \\
\hline \multirow[t]{2}{*}{0.05} & \multirow[t]{2}{*}{0.7} & \multirow[t]{2}{*}{$\begin{array}{c}80-20-0 \\
0-95-5 \\
5-95-0 \\
80-18-2 \\
90-10-0 \\
5-95-0 \\
0-100-0 \\
0-95-5 \\
0-98-2 \\
5-95-0\end{array}$} & $\begin{array}{l}0-40-60 \\
0-80-20 \\
0-70-30 \\
0-80-20 \\
0-80-20 \\
0-60-40 \\
0-85-15 \\
0-60-40 \\
0-40-60 \\
0-80-20\end{array}$ & $\begin{array}{r}70 \\
8 \\
18 \\
49 \\
55 \\
23 \\
7 \\
18 \\
30 \\
12\end{array}$ & $\begin{array}{l}60 \\
15 \\
30 \\
18 \\
20 \\
40 \\
15 \\
35 \\
58 \\
20\end{array}$ & $\begin{array}{l}8 \cdot 2 \\
3 \cdot 9 \\
5 \cdot 5 \\
5 \cdot 1 \\
5 \cdot 4 \\
6 \cdot 3 \\
3 \cdot 9 \\
5 \cdot 9 \\
7 \cdot 6 \\
4 \cdot 5\end{array}$ \\
\hline & & & $\begin{array}{l}\text { Mean } \\
\text { S.D. }\end{array}$ & $\begin{array}{l}29 \cdot 0 \\
21 \cdot 7\end{array}$ & $\begin{array}{l}31 \cdot 1 \\
16 \cdot 9\end{array}$ & $\begin{array}{l}6.63 \\
1 \cdot 44\end{array}$ \\
\hline \multirow[t]{2}{*}{$0 \cdot 10$} & \multirow[t]{2}{*}{$1 \cdot 0$} & \multirow[t]{2}{*}{$\begin{array}{c}5-95-0 \\
0-95-5 \\
2-96-2 \\
5-85-10 \\
0-98-2 \\
0-100-0 \\
0-100-0 \\
10-90-0 \\
5-95-0 \\
5-95-0\end{array}$} & $\begin{array}{l}0-10-90 \\
0-40-60 \\
0-40-60 \\
0-45-55 \\
0-70-30 \\
0-60-40 \\
0-40-60 \\
0-60-40 \\
0-20-80 \\
0-10-90\end{array}$ & $\begin{array}{l}48 \\
28 \\
31 \\
25 \\
15 \\
20 \\
30 \\
25 \\
43 \\
48\end{array}$ & $\begin{array}{l}90 \\
55 \\
58 \\
45 \\
28 \\
40 \\
60 \\
40 \\
80 \\
90\end{array}$ & $\begin{array}{l}9 \cdot 5 \\
7 \cdot 4 \\
7 \cdot 6 \\
6 \cdot 7 \\
5 \cdot 3 \\
6 \cdot 3 \\
7 \cdot 7 \\
6 \cdot 4 \\
8 \cdot 9 \\
9 \cdot 5\end{array}$ \\
\hline & & & $\begin{array}{l}\text { Mean } \\
\text { S.D. }\end{array}$ & $\begin{array}{l}31 \cdot 3 \\
11 \cdot 4\end{array}$ & $\begin{array}{l}58 \cdot 6 \\
21 \cdot 7\end{array}$ & $\begin{array}{l}7.53 \\
1.42\end{array}$ \\
\hline
\end{tabular}

* Maturation Value (MV), Superficial Cell Index (SCI) and Dynamic Oestrogenicity Index (DEI)

From a large group of amenorrhoeic women treated with three different doses of mestranol $(0.02,0.05$ and $0.1 \mathrm{mg}$ daily for 10 days $)$, thirty women were randomly selected, ten from each dosage group.

The results, i.e. the initial and terminal maturation indices before and after 
treatment and the calculated oestrogenic effects $(\Delta \mathrm{MV}, \Delta \mathrm{SGI}$ and DEI) are presented in Table 1 . Mean values with corresponding standard deviations plotted against the log of the daily doses are shown in Text-fig. 1, and the corresponding regression calculations in Table 2.

As may be seen, the difference in maturation values before and after treatment $(\Delta M V)$ is the poorest representation of the vaginal epithelial response.

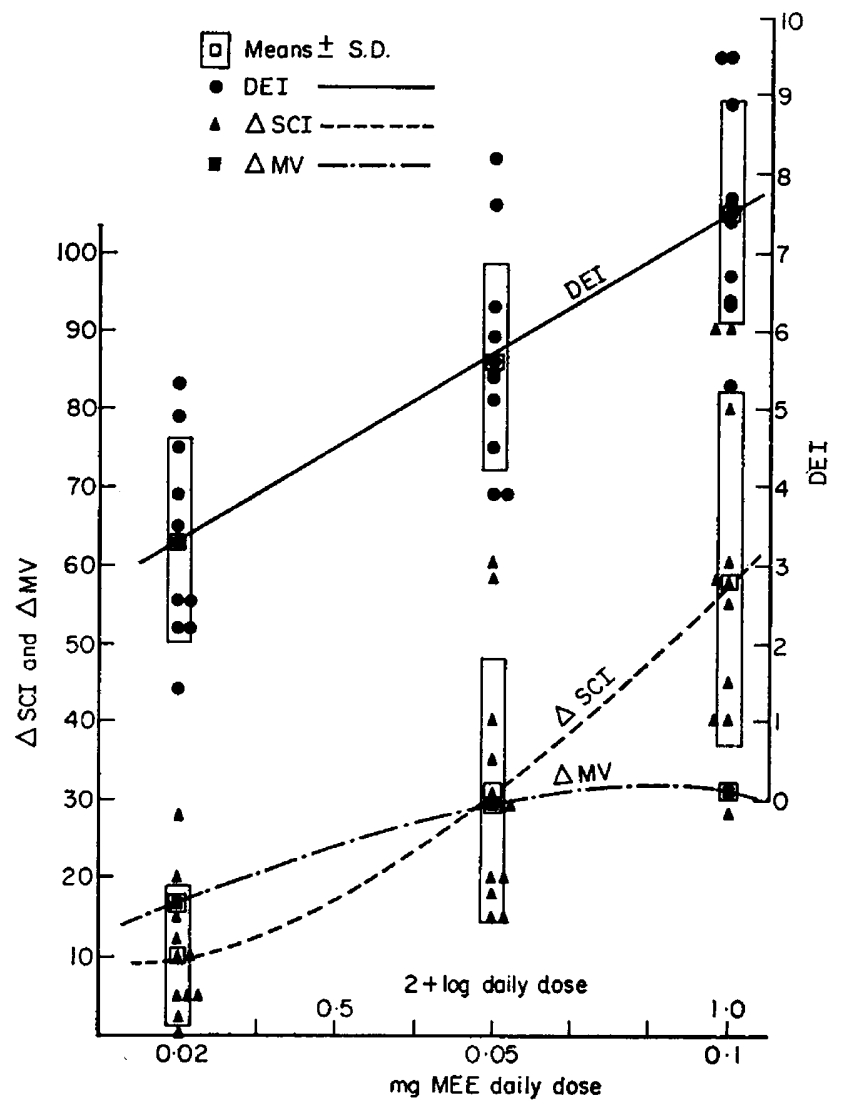

TexT-FIG. 1. Relationship between three different oestrogenicity indices Superficial Cell Index (SCI), Maturation Value (MV) and Dynamic Oestrogenicity Index (DEI) and $\log$ dose of mestranol (MEE). The oestrogen was administered to amenorrhoeic women (showing no endogenous oestrogen activity) over a period of 10 days. The $\Delta \mathrm{SCI}$ and $\Delta \mathrm{MV}$ values are the differences of the respective indices between their initial and terminal values. Since the changes in $\Delta M V$ were slight, no S.D.s were indicated.

Differences in respective SCIs are much more sensitive to the oestrogen dose but the relationship is non-linear, and the dispersion of individual results is much greater at higher doses than at the low ones. In contrast to this, the relationship between the vaginal response, expressed as DEI, and the log dose of oestrogen was linear over the range of doses investigated and the dispersion was quite uniform, independent of the dose. Thus, use of the DEI seems to be the best approach to the problem of comparing the oestrogenic effects of different steroids on the vaginal epithelium in women. 
In order to avoid interference from endogenous hormones, only women with non-functioning ovaries (amenorrhoea, premature ovarian failure) or with no ovaries (pure gonadal dysgenesis, young patients subjected to bilateral ovariectomy) are adequate for testing oestrogenic compounds (Wied \& Davis, 1958).

TABLE 2

REGRESSION ANALYSIS AND PREGISION INDICES $(\lambda)$ GALGULATED FOR THREE DIFFERENT MEASURES OF OESTROGENICITY

\begin{tabular}{c|cccccccc}
\hline $\begin{array}{c}\text { Measure of } \\
\text { oestrogenicity }\end{array}$ & \multicolumn{1}{|c}{$S_{x \boldsymbol{x}}$} & \multicolumn{1}{c}{$S_{x y}$} & \multicolumn{1}{c}{$S_{y y}$} & $S_{y y}-\frac{S^{2}{ }_{x y}}{S_{x x}}$ & d.f. & $s_{y \cdot x}$ & $b$ & $\lambda$ \\
\cline { 2 - 9 } MV & $2 \cdot 467$ & $52 \cdot 8$ & 9503 & 8373 & 28 & $17 \cdot 3$ & $21 \cdot 4 *$ & $0 \cdot 81$ \\
SCI & $2 \cdot 467$ & $168 \cdot 3$ & 19326 & 7843 & 28 & $16 \cdot 7$ & $68 \cdot 2$ & $0 \cdot 24$ \\
DEI & $2 \cdot 467$ & $14 \cdot 8$ & 142 & 53 & 28 & $1 \cdot 4$ & $6 \cdot 0$ & $0 \cdot 23$ \\
\hline
\end{tabular}

* Regression non-significant.

Explanation of symbols:

$$
\begin{array}{ll}
S_{x x}=\Sigma x^{2}-\frac{(\Sigma x)^{2}}{n} & S_{y . x}=\sqrt{\frac{1}{n-2}\left(S_{y y}-\frac{S^{2}{ }_{x y}}{S_{x x}}\right)} \\
S_{x y}=\Sigma_{x y}-\frac{\left(\Sigma_{x}\right)\left(\Sigma_{y}\right)}{n} & b=\frac{S_{x y}}{S_{x x}} \\
S_{y y}=\Sigma y^{2}-\frac{(\Sigma y)^{2}}{n} & \lambda=\frac{s_{y, x}}{b}
\end{array}
$$

Furthermore, when such patients have been previously treated with oestrogens, care should be taken to suppress the oestrogenic effects and administration of the compound should be postponed until parabasal and small intermediate cells, as well as leucocytes, have appeared in the vaginal smear.

The authors are grateful to Mr A. J. Wilson (Searle Labs., High Wycombe, England) for the generous supply of mestranol.

\section{REFERENCES}

FisHeR, R. A. (1948) Statistical methods for research workers, 10th edn. Oliver \& Boyd, Edinburgh.

Frost, J. K. (1961) Concepts basic to general cytopathology, 2nd edn. Johns Hopkins Press, Baltimore.

Haskins, A. L., Moszkowski, E. F. \& Whitelock, V. P. (1968) The estrogenic potential of estriol. Am. F. Obstet. Gynec. 102, 665.

Mersels, A. (1967) The maturation value. Acta cytol. 11, 249.

Meisers, A. (1968) Moderator: what is a 'normal' or 'acceptable' within-slide variance if three technicians count the same index on the same slide? Acta cytol. 12, 99.

Pundel, J. P. (1968) Symposium on hormonal cytology. Acta cytol. 12, 103.

SNedecor, G. W. (1956) Statistical methods, 5th edn. The Iowa State College Press, Ames, Iowa.

Teter, J. (1968) Symposium on hormonal cytology. Acta cytol. 12, 107.

WrED, G. J. (1968) Cytologic indices for hormonal assessment. Acta cytol. 12, 87.

WIED, G. J. \& DAvis, M. E. (1958) Comparative activity of progestational agents on the human endometrium and vaginal epithelium of surgical castrates. Ann. N.Y. Acad. Sci. 71, 599. 